Larkin, S. et al. (2011-01-21), "Practical Considerations in Using Bioeconomic Modelling for Rebuilding Fisheries", OECD Food, Agriculture and Fisheries Papers, No. 38, OECD Publishing, Paris.

http://dx.doi.org/10.1787/5kgk9qclw7mv-en

\title{
OECD Food, Agriculture and Fisheries Papers No. 38
}

\section{Practical Considerations in Using Bioeconomic Modelling for Rebuilding Fisheries}

Sherry L. Larkin,

Sergio Alvarez,

Gil Sylvia,

Michael Harte 


\section{Practical Considerations in Using Bioeconomic Modelling for Rebuilding Fisheries}

Sherry L. Larkin and Sergio Alvarez

University of Florida, Gainesville, Florida, United States

Gil Sylvia

Oregon State University, Newport, Oregon, United States

Michael Harte

Oregon State University, Corvallis, Oregon, United States

OECD FOOD, AGRICULTURE AND FISHERIES

WORKING PAPER No. 38 


\section{OECD ON FOOD, AGRICULTURE AND FISHERIES WORKING PAPERS}

This working paper series is designed to make available to a wide readership selected studies by OECD staff or by outside consultants, and are generally available only in their original language, English or French.

The opinions expressed in these papers are the sole responsibility of the author(s) and do not necessarily reflect those of the OECD or the governments of its member countries.

Comment on the series is welcome, and should be sent to tad.contact@oecd.org.

OECD FOOD, AGRICULTURE AND FISHERIES WORKING PAPERS are published on www.oecd.org/agriculture

(C) OECD 2011

Applications for permission to reproduce or translate all or part of this material should be made to: OECD Publishing, rights@oecd.org or by fax 33145249930. 


\begin{abstract}
Many of the world's fish stocks are considered to be in need of rebuilding. In response, global agreements, including UNCLOS, have sought to adopt some (optimal) level of fish biomass, usually the level associated with the maximum sustainable yield (MSY). While establishing a sustainable level of harvest is goal with intuitive appeal, the pursuit of MSY ignores many relevant economic and social factors that are critical to the sustainability of a fishery.

This paper first discusses the important distinction between rebuilding stocks and rebuilding fisheries and then discusses the use of bioeconomic modelling for developing rebuilding strategies. To facilitate this discussion, we briefly summarize the theory of bioeconomic modelling, including a description of what constitutes a bioeconomic model and why it should be considered for use in management (particularly for managing a fishery during rebuilding). Next, we discuss the role of bioeconomic modelling within a management strategy evaluation (MSE) framework. Following the description of these tools, we examine the use of bioeconomic models to address several five commonly held paradigms regarding rebuilding that are tantamount to fallacies. The paper concludes with the presentation of a variety of case studies that illustrate how bioeconomic models have been used to inform the management process worldwide. Lastly, practical information on the use of bioeconomic models in developing fisheries policy is summarized
\end{abstract}

JEL Classification: Q22, Q27, Q27

Keywords: Bioeconomic Modelling; Fisheries Rebuilding; Striped bass; Northern Prawns; North Atlantic Cod; Spiny Lobster; Norwegian Spring Spawning Herring; Fisheries Economics; Fisheries Management

\title{
Acknowledgements
}

We wish to thank the OECD for their support of this effort. We especially appreciated the comments by the OECD Committee for Fisheries and Saba Khwaja that greatly improved the structure and content of the paper. We would also like to acknowledge all bioeconomic researchers whose literature we have made reference to and to the countless others that have shaped our arguments in subtle ways but are not explicitly referenced - and there are many. All arguments and summary comments, including any errors, are ours alone and should not reflect poorly on any of the authors cited here 



\section{Table of contents}

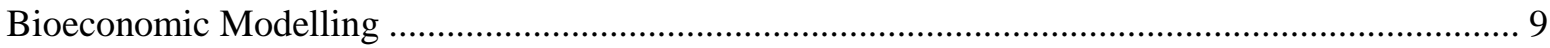

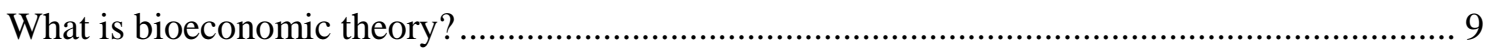

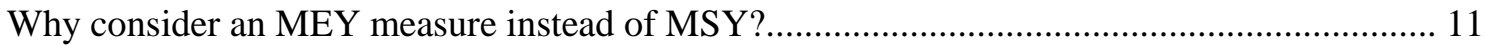

How can bioeconomic analysis be used for rebuilding? ........................................................ 14

How is bioeconomic modeling for rebuilding different

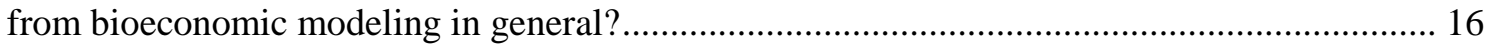

How does bioeconomic modeling relate to management strategy evaluation (MSE)? ............... 16

Use of bioeconomic models to address fallacies in rebuilding fisheries .......................................... 18

Bioeconomic models for rebuilding fisheries: applications......................................................... 24

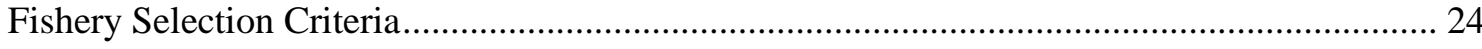

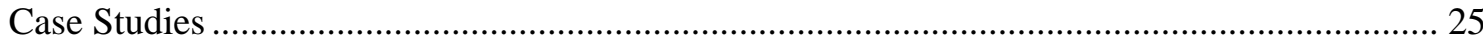

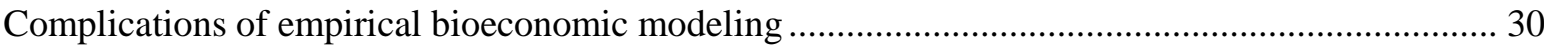

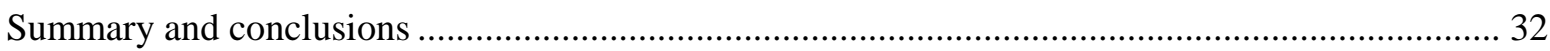

\section{Boxes}

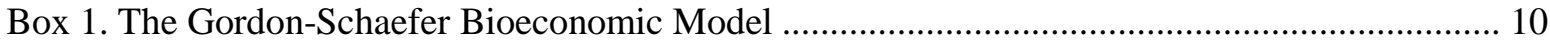

Box 2. The Effect of Time Horizon and Discounting in Rebuilding in United States

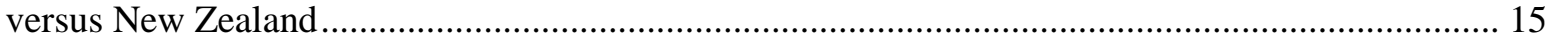

\section{Tables}

Table 1. Role of Economic Factors in Determination of MEY or Optimal Harvest using a Logistic Growth and CPUE Production Function 



\section{PRACTICAL CONSIDERATIONS IN USING BIOECONOMIC MODELING FOR REBUILDING FISHERIES}

Nearly two-thirds of assessed fish stocks worldwide may be in need of rebuilding (Worm et al., 2009). This is not encouraging since nations have been obligated to manage fish stocks to produce the maximum sustainable yield (MSY) since the 1982 United Nations Convention for the Law of the Sea (UNCLOS). By 1994, the UNCLOS agreement had been ratified by 158 countries and the European Union. The international agreement to use MSY as a policy goal was reinforced with the Johannesburg Plan of Implementation (2002). Under this agreement, the European Union, Norway, Russia and Iceland will rebuild their fish stocks to the level that can produce MSY by 2015. In the United States, depleted populations must be rebuilt to the MSY within 10 years if biologically possible and plans must be implemented in 2010. Other nations are also likely to have the biologically-based MSY as a policy objective since it has intuitive appeal. This is because the MSY is a long-run equilibrium concept that would provide a sustainable supply at the highest level possible; therefore, it implies efficiency and maximized revenues.

Bioeconomic modelling has long been advocated as an important tool in managing fisheries for determining the sustainable levels of catch and effort and the exploitation path to achieve those equilibrium levels, particularly for rebuilding (Clark, 1985, 1990; Hannesson, 1993; Seijo et al., 1998; Anderson and Seijo, 2009). This is because a bioeconomic model of a fishery combines the underlying stock dynamics with the harvest function and the costs of harvest and economic value of the extracted resources (whether retained or discarded). Such a model can address, for example, how quickly a fishery can be rebuilt in terms of being sufficiently confident that stocks are increasing while ensuring a level of harvest to maintain employment and markets. Bioeconomic models accomplish this by specifying a policy objective (e.g. maximize landed value, landings, employment, or any combination) to determine prescribed catch and/or effort levels that consider the salient characteristics of both the stock and the fishery. Bioeconomic models allow us to incorporate the interaction between fishing behaviour and the biology of the stock through effort and catch, whose optimal values (i.e. those that maximize the objective) are mutually dependent. The simplest bioeconomic models are used to provide an estimate of the sustainable catch and corresponding effort level that results from a value-based objective function; this is known as the solution that maximizes the economic yield (MEY).

The MEY explicitly considers the interests of the harvesters in addition to the necessary biological dynamics by including a harvest (i.e. production) function that translates fishing effort into catch. This function, and the resulting measure of net economic value of the resource, is considered crucial at the policy level since fishing is inherently an anthropocentric activity. In contrast, the MSY does not account for the costs of harvest, which are often stock dependent. This is why most economists advocate for consideration of the MEY by policy makers. 
Since bioeconomic modelling can incorporate some elements of human decision making, it is a tool that is most effective for modelling fisheries and not simply the resource stocks in a fishery. While this distinction may seem obvious, it is critical when thinking about stocks that are considered to be at levels that are too low. If fishery managers have concluded that the level of a stock is too low and, therefore, want to manage the fishery to operate at a higher stock level, that is most aptly referred to as "stock rebuilding." This scenario is contrasted with the desire of fishery managers to improve the fishing industry, which may or may not involve increasing stock size. This latter scenario is more aptly referred to as "fisheries rebuilding" since it inherently involves the human dimension. While considering a stock that is undergoing overfishing or is overfished is an important category of fisheries that are in need of rebuilding, fisheries may need rebuilding for purely social or economic reasons.

This paper will focus on the use of bioeconomic modelling for developing rebuilding strategies. Bioeconomic approaches are particularly useful where fisheries laws allow consideration of economic, social, and cultural considerations in developing optimal rebuilding plans. This is because fisheries may need rebuilding for reasons unrelated to the biological characteristics of the stock. These reasons include anything that affects the decisions of fisherman such as changes in the management of the fishery, general economic conditions, the profitability of fishing, the demand for alternative uses of the stock, the supply of substitutes, trade patterns and consumer preferences. Bioeconomic models can also be used to help managers balance the risk to protecting fishery stocks against the economic and social risks to fishermen, processors, and the communities that depend on their activities. Bioeconomic models, if properly used, can help managers develop objective analysis in order to select rebuilding strategies that have the best chance to maximize social welfare.

First, we summarize the theory of bioeconomic modelling, beginning with what constitutes a bioeconomic model and why it should be considered for use in management and particularly for managing a fishery during rebuilding. Next, we briefly discuss the role of bioeconomic modelling within a management strategy evaluation (MSE) framework, which is a technique for implementing adaptive management in fisheries. Following the description of these tools, we examine the use of bioeconomic models to address several five commonly held assumptions regarding rebuilding that are presented as paradigms with respect to rebuilding fisheries. The paper concludes with the presentation of a variety of case studies that illustrate how bioeconomic models have been used to inform the management process worldwide. Lastly, practical information on the use of bioeconomic models in developing fisheries policy is summarized. 


\section{Bioeconomic modelling}

\section{What is bioeconomic theory?}

As the name implies, bioeconomic theory in fisheries combines the biological and economic aspects of a fishery to explain stock, catch, and effort dynamics under different regimes, and provide insights on the optimal management of the stock. This is accomplished by specifying an objective function that is usually based on the value of the harvest across space and time, and constraints representing the biological characteristics of the stock and requirements of the management process. Consequently, the optimal level of effort is determined not only by the biological dynamics of the stock but also by the cost structure of the fishery and the value of the harvest. This solution process is distinguished from financial analysis because it explicitly incorporates the opportunity costs of the harvest, usually in the form of a time stream of discounted net benefits representing a specific pattern of harvests and stock levels.

Bioeconomic theory was pioneered by Gordon (1954), and Schaefer's (1954) static model of a single species commercial fishery is commonly used to describe and compare equilibrium solutions (Box 1). The Gordon-Schaefer model illustrates the economic inefficiency of an open-access fishery (referred to as the open access equilibrium or OAE) compared with the economically efficient outcome that maximizes long run rents (i.e. the MEY).

Dynamic analysis of the fishery was introduced in the mid 1950s and expanded in the mid 1980s with the introduction of optimal control theory. Delay-difference models could now capture the direct effect that fishing has on subsequent recruitment. Year-class or cohort models expanded on delay-difference models by differentiating the individuals in a stock by age or size, allowing researchers to investigate the effects of gear restrictions including net design or hook size. Multi-species models are becoming more important to account for interactions in mixed species fisheries or where ecosystem relationships are important (Eggert, 1998). A notable feature of the different dynamic models is the similarity of their broad conclusions to those of the basic Gordon-Schaefer model (Clark, 2006a). Perhaps it is this feature that makes most dynamic models seem unnecessary or too complex to be implemented in fisheries management, and it may explain why singlespecies models are often favoured for problems that do not involve spatial heterogeneity or ecosystems.

To summarize, bioeconomic modelling can be static (to determine the sustainable equilibriums) or dynamic (to model transitions and exploitation paths), the objective can reflect the status quo or a proposed alternative (e.g. maximize effort, resource rents, or a combination), and the solution can be deterministic or stochastic. The only correct bioeconomic model is one that adequately captures the fishery for the current purpose of management. Over time, bioeconomic models could be developed and refined as policy needs change, parameters change and data becomes available. The only caveats are that a bioeconomic model is only as strong as its weakest link, which could be from missing data or overly simplistic assumptions on either the biology or economics. In addition, bioeconomic models need to be based on an explicit objective of managers (and the corresponding control variable) that uses economic and biological information to affect the solution. Most importantly, if rebuilding is the objective then a dynamic model that examines the path to the objective (either biomass level for stock rebuilding or profit level for fisheries rebuilding) is necessary. 


\section{Box 1. The Gordon-Schaefer Bioeconomic Model}

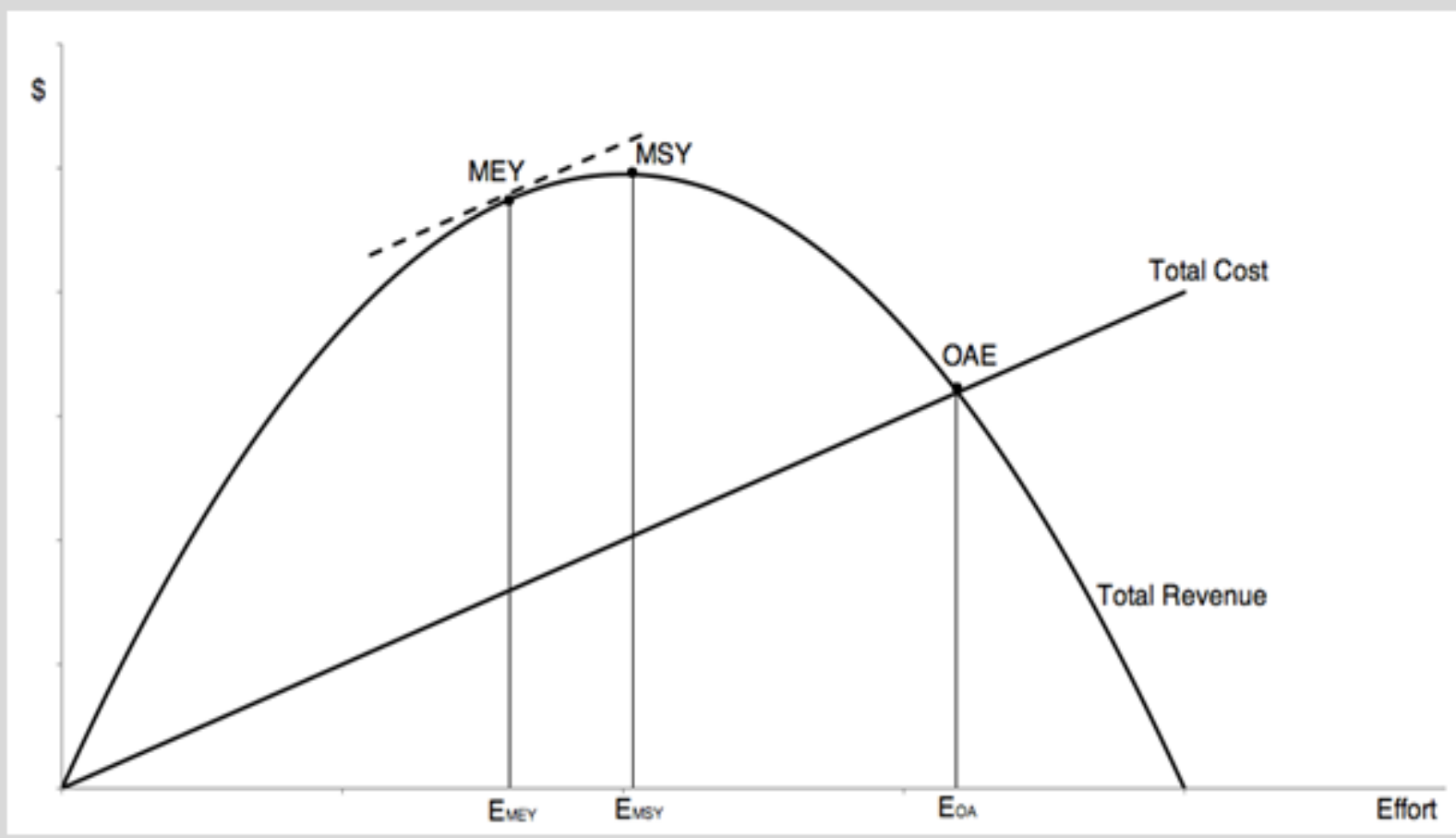

The economics of a commercial fishery can be illustrated using a two dimensional graph that shows cost and revenue on the $y$-axis and fishing effort on the $x$-axis. For simplicity, we can assume that cost increases linearly with effort, resulting in the total cost curve shown above. Revenue from fishing is given by the product of a constant price of fish landed and the catch, which is also a function of effort. The most common single species biological model uses a logistic growth function that produces a revenue function of the shape depicted in the total revenue curve shown above. In a commercial fishery at relatively low levels of effort, increasing effort will increase revenues but the revenues will begin to decline as less fish can be sustainably harvested at the higher effort levels. If too much effort is used the fish stock will become extinct and revenues from fishing will be zero.

The highest catch can be achieved at the point labelled MSY, or maximum sustainable yield. At this point, both the revenue function and the sustainable yield function are at their maximum.

In an undeveloped fishery (where fishing effort is zero) fishermen will be attracted into the fishery since the effort they invest will generate a positive return (i.e. the revenue curve lies above the cost curve). The fishery will continue to attract effort (additional fishermen or more effort by the same fishermen) until the returns from fishing just equal the cost of fishing. This is the point labelled OAE, or open-access equilibrium. At this point, the fishery has dissipated all resource rents (i.e. profits in the special case where costs are measured as opportunity costs). If the fleet is heterogeneous, some fishermen are likely to earn economic profits while others incur losses at this point (i.e. earn intra-marginal and extra-marginal rents, respectively).

If the fishery were managed by a single entity, the fishery would be managed to maximize resource rents. That is, the owner would use the amount of effort that would yield the largest difference between revenues and costs. This occurs at the point labelled MEY, or maximum economic yield. At this point the EMEY is the most socially desirable level of effort because it is generating the highest net returns possible and indicating an efficient use of resources devoted to fishing. 
Bioeconomic modelling, however, is not a panacea for the problems that fisheries are currently facing. Instead, it is part of a solution that requires various elements from different disciplines. Specifically, the bioeconomic model can provide information about the possible improvements in profitability of the fishing fleet when steps towards stock recovery are taken. This is the "necessary incentive" discussed by Munro (2009). Such a model can provide a suite of rebuilding trajectories and timeframes and evaluate tradeoffs between, important objectives including revenue, profit, income, and economic and biological risks. Managers and stakeholders can then use this information to select the "best" approach that balances these objectives in a way that seems reasonable to a majority of stakeholders, as it makes explicit that the management objective is recovery of the stock in the most profitable manner. The most effective way to communicate this is through the use of graphs that show projected landings, revenues, and costs. In fact, showing this information is critical to describing the salient features of analyses that attempt to estimate and compare the net benefits of alternative rebuilding scenarios. This approach would, for example, be able to convey the effect of a buyout program (through a high fixed cost in year 0) or key assumptions on how costs change over time (e.g. do they increase as harvests increase or decrease due to improved efficiency from the buyout program?) that are often otherwise difficult to ascertain. With such graphs, fishermen can easily provide input as to the relative realism of these key economic assumptions.

Regardless of the particular type of model, bioeconomic models are inherently descriptive rather than prescriptive (i.e. positive versus normative). An applied bioeconomic model of a commercial fishery, for instance, can describe the difference in the level of effort used for harvesting between the open-access and the optimal rentmaximizing outcome. Such a model can also be use to simulate or extrapolate the consequences of various policy actions in the future by comparing the net present values. The researcher conducting the study can then prescribe some target level of effort that should move the fishery towards a more economically efficient level of fishing effort and consequently to a more socially desirable harvest level. Thus, an optimized bioeconomic model is a representation of "what is" based on the defined components of the model and what "should be" in terms of the scope of the model; what the appropriate policy action "should be", however, needs to consider any additional factors that society considers relevant to the management plan.

\section{Why consider an MEY measure instead of MSY?}

The fact that the MEY solution considers the economic characteristics of the fishery is a statement about the methods used to derive the solution and not a justification for using it in management. All too often, especially for overfished stocks, economics is blamed for causing the need for rebuilding. But the MEY solution is best characterized as one that considers the economic efficiency associated with the sustainable yield curve, and there are a number of salient benefits for pursuing such a goal - or at least evaluating it for any given fishery. First, since the solution is characterized by one where the difference between benefits and costs are the greatest, profits will always be maximized. This is important because it means that the approach is responsive to changes in economic conditions such as the price of the product and harvesting costs. Second, the implication of efficiency (i.e. using just the resources that are needed in the fishery and no more) is that excess resources (i.e. capital) can be used alternatively in the economy. This is because in an economic analysis (as opposed to a financial analysis) all costs are measured as "opportunity costs," which reflect their relative value (in their next best use) from an economy-wide, and not just fishing, perspective. Third, the MEY solution is one 
that minimizes harvesting costs, which can help improve the competiveness of a product. Minimizing costs can also provide an industry with resiliency to exogenous negative shocks. By contrast, the MSY solution has no direct relationship with economic characteristics of the fishery and can generate zero or even negative profits (Kompas et al., 2009). Thus, the fourth reason why MEY might be considered preferable to the MSY as a management goal is that the MSY solution compromises the ability of a commercial fishery to remain viable ${ }^{1}$. Lastly, under reasonable bioeconomic assumptions, MEY may be associated with a larger equilibrium stock size than MSY (Grafton et al., 2007).

Certainly one of the most compelling reasons to consider the bioeconomic (MEY) solution as a means of evaluating a fishery is that it models the efficient use of resources. The fact that the MEY solution is responsive to changes in the economic conditions of the fishery, it is useful to explore how the single species model reacts to such realities. To that end, Table 1 summarizes how the optimal bioeconomic solution (as compared to Box 1) will change as prices, costs, and the discount rate increase or decrease. The last column of the table also describes how these economic parameters can be modelled endogenously and the hypothesized effect on the MEY solution.

It should be clear that static solutions can be used to set a target rebuilding objective, while dynamic models can be used to examine the efficient path. What needs to be considered, however, and is not discussed in detail here, are the realities of using MEY for fisheries management (Dichmont et al., 2010). This is where the majority of literature on rights-based fishing is concentrated. A rights-based system may be needed in order to reach and sustain the MEY solution since the use of traditional input and output controls is seriously flawed with respect to achieving efficient solutions (e.g. Kompas et al., 2009). That said, the need to consider the role of the governance system is independent of the objective; it is a characteristic of any rebuilding plan.

1. Using the figure in Box 1, consider a fishery facing higher harvest costs (e.g. the cost of fuel increased). Higher variable costs will rotate the total cost (TC) curve upward. If the cost increase causes the TC curve to intersect the total revenue (TR) curve to the left of the MSY, then profits will be negative at the MSY effort level. 
Table 1. Role of Economic Factors in Determination of MEY or Optimal Harvest Path using a Logistic Growth and CPUE Production Function

\begin{tabular}{|c|c|c|}
\hline $\begin{array}{c}\text { Economic Factor } \\
\text { (Role in MEY Solution) }\end{array}$ & $\begin{array}{c}\text { Constant Specification } \\
\text { (comparative statistics } \\
\text { of } \uparrow)^{*}\end{array}$ & $\begin{array}{c}\text { Endogenous Function } \\
\text { (potential effect } \\
\text { during rebuilding) }\end{array}$ \\
\hline $\begin{array}{l}\text { Product price } \\
\text { (determines peak of TR curve) } \\
\qquad \$\end{array}$ & $\begin{array}{l}\text { Harvest more (leave a smaller } \\
\text { stock), use more effort from } \\
\text { change in peak of TR curve. }\end{array}$ & $\begin{array}{l}\text { Inverse with total catch: price } \\
\text { will fall as rebuild stock but } \\
\text { higher price helps fishery } \\
\text { initially unless the product is a } \\
\text { 'commodity' with a lot of } \\
\text { competition }\end{array}$ \\
\hline
\end{tabular}

\section{Variable harvest cost}

(determines slope of TC curve)

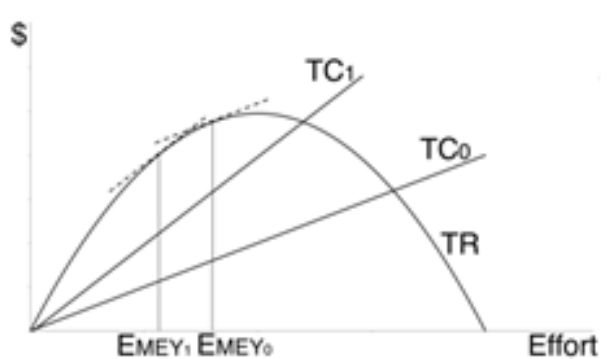

Harvest less from increase in slope of TC curve (leave a larger stock), use less effort.
Inverse with total stock size: costs fall as rebuilding succeeds. This effect may only be relevant for stocks with certain characteristics. This effect compounds that of also specifying an endogenous price. Key implication is costs rise as stocks fall, especially if convex, model will leave larger stock.

\begin{tabular}{|c|c|c|}
\hline $\begin{array}{l}\text { Fixed costs } \\
\text { (determines height of TC curve) } \\
\$\end{array}$ & $\begin{array}{l}\text { Reduce profits but does not } \\
\text { change the MEY (harvest, stock } \\
\text { or effort) since the slope of the } \\
\text { TC does not change. }\end{array}$ & $\begin{array}{l}\text { Not applicable. Fixed costs } \\
\text { are usually only a function in } \\
\text { the sense of having fixed } \\
\text { costs vary by gear type or type } \\
\text { of ownership (sole proprietor } \\
\text { versus corporation). If so, will } \\
\text { affect the allocation between } \\
\text { stakeholder groups if net } \\
\text { benefits are a criteria. }\end{array}$ \\
\hline$E_{M E Y_{0}}=E_{M E Y}$ & & \\
\hline $\begin{array}{l}\text { Discount rate } \\
\text { (not directly observable in simple model; although } \\
\text { if zero, MSY = MEY) }\end{array}$ & $\begin{array}{l}\text { Harvest more, earlier in a } \\
\text { dynamic model since value is } \\
\text { relatively higher (leave a smaller } \\
\text { stock), use more effort. }\end{array}$ & $\begin{array}{l}\text { Not applicable. Although } \\
\text { hyperbolic rates have been } \\
\text { discussed, this parameter } \\
\text { usually does not vary over } \\
\text { time or individuals unless } \\
\text { there is evidence of different } \\
\text { time preferences for money. }\end{array}$ \\
\hline
\end{tabular}

* The comparative statics of a decline in each parameter would be the opposite as for the increase. 


\section{How can bioeconomic analysis be used for rebuilding?}

To our knowledge only two recent stylized bioeconomic studies (i.e. general numerical examples not specific to an actual real-world fishery) have explicitly addressed the issue of rebuilding fisheries. Agar and Sutinen (2004) considered the impacts of different rebuilding strategies in a multi-species fishery. More specifically, they considered alternative gear restrictions and non-selective technologies by changing the catchability of the over- and under-exploited species. These rebuilding strategies were then analyzed within the context of biological predator-prey interactions between the species and economic cost interdependencies in the fishing of the two species. Rebuilding outcomes were found to vary considerably with the type of technology employed (as proxied by changing the catchability coefficient) and the presence of cost and biological interactions. In particular, consideration of biological interactions drastically increased the ambiguity of the outcome, and different combinations of interactions and technologies were found to further deplete the stock rather than rebuild it. They conclude that the failure to consider such interdependencies may negatively affect rebuilding efforts.

Larkin et al. (2006) consider the effects of different rebuilding timeframes under different discount rates on the annual sustainable catch and the net present value of benefits of harvesting fish from two different populations: a moderate-lived species and a long-lived species. An age-structured dynamic bioeconomic model was developed to account for the different cohorts. Net benefits were calculated using price and variable cost functions that were inversely proportional to landings and spawning biomass, respectively. Fixed costs were held constant. Tradeoffs between rebuilding timeframes, average harvest levels and the value of the fishery were examined. The results highlighted the importance of bioeconomic models when a fishery faces rigid rebuilding guidelines. In contrast to several recent high profile studies showing that benefits are maximized by rebuilding as fast as possible (e.g. Sumaila and Suatoni, 2005, and Gates, 2009), the use of a bioeconomic model in this study found that delayed rebuilding can considerably increase average harvest levels and benefits. The magnitude of the tradeoffs are depicted in Box 2.

Box 2 shows that moving from a 40-year rebuilding timeframe for a 70-cohort overfished stock (which is about as quick as possible as would be mandated in the United States), to a 50- or 60-year rebuild (as would be allowed in New Zealand) would produce considerable gains in both average harvest levels and the value of the fishery. Using the $4 \%$ discount rate and slowing the rebuilding target by a decade, would increase average harvest levels by $93 \%$ on average since the model allows for fishing through the rebuilding period. The associated benefits of this slower rebuild are that the net present value increases $58 \%$, due in part to the higher product price from low stock levels in the early years. Thus, mandating rebuilding only on biological criteria may produce significant economic losses, particularly for slow-growing stocks in fisheries with high discount rates.

There is a perceived risk of extinction that is associated with allowing a fishery to remain open during periods of low stock levels that is so great as to justify a closure, despite the negative economic consequences associated with closures (Paradigm 1). This 
argument is supported with historical evidence of overfished stocks that have been unable to recover (e.g. Safina et al., 2005; Rosenberg et al., 2006, Worm et al., 2009). ${ }^{2}$

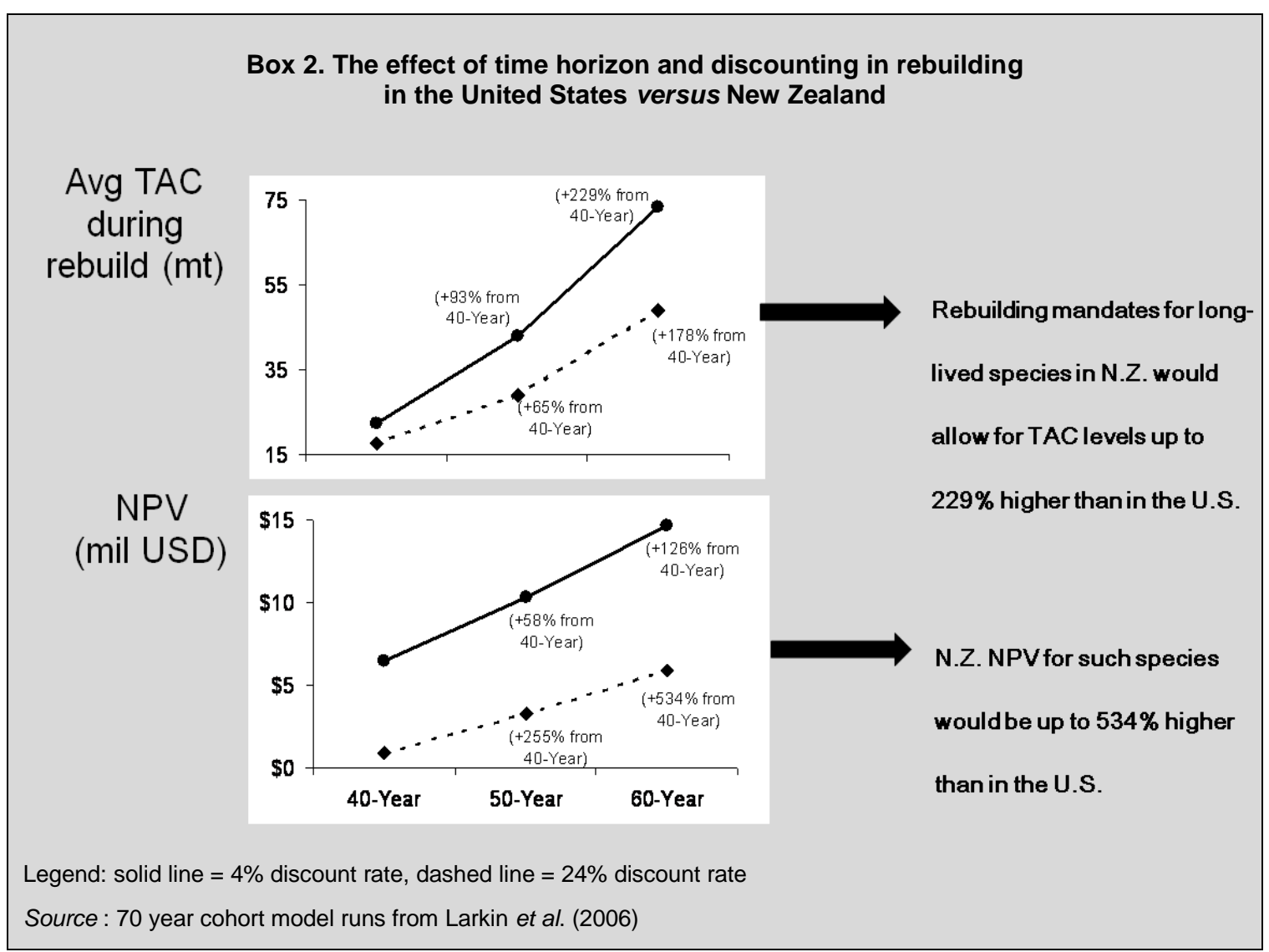

However, as Larkin et al. (2006) has shown, rebuilding stocks as fast as biologically possible has real social costs. Balancing these costs with the risk of lower than expected stock growth or possible risk of extinction can be evaluated within bioeconomic models that explicitly evaluate biological and economic risks. Perhaps this is where a bioeconomic model and the management strategy evaluation (MSE) approach can provide the greatest benefit, that is, by showing how interim target reference points (e.g. stock growth) can be routinely evaluated - and addressed through an appropriate policy change if necessary - to ensure that the exploitation path is being followed. Such an approach could lower these risks over time.

From an economic perspective of using bioeconomic models for evaluating rebuilding, these two studies highlight the different types of economic information that is necessary for analysis. The Agar and Sutinen (2004) study focused on interdependent costs between fisheries and differences in catchability coefficients across gear types. In contrast, he study by Larkin et al. (2006) looked at moderate to long lived species, dependent price, variable cost functions, and different discount rates. Each paper illustrated a subset of issues that may be relevant in rebuilding and managing stocks.The

2. The lack of recovery is most often attributed to myopic fishermen that exert undue influence on managers. The underlying incentives of fishermen are, however, determined by the governance structure (i.e. continued use of command and control tools). 
former was interested in predator-prey stock interactions and the relationship with fishing technology, the latter was interested in the difference of binding rebuilding timeframes for stocks with different cohort characteristics.

\section{How is bioeconomic modelling for rebuilding different from bioeconomic modelling in general?}

The most recognizable bioeconomic model is where a single stock is harvested by a single homogeneous fishing fleet (Boxes 1 and 2). Such a model determines a combination of a harvest level and effort level that maximizes the net present value of harvests under identical conditions in perpetuity. This "equilibrium" solution is considered the sustainable economic solution that produces maximum economic yield (MEY) and is an alternative to a biological solution of maximizing the harvest level over time or maximizing the sustainable yield (MSY). The divergence of these two solutions provides policy advice from a 'bioeconomic' perspective. Such an approach can be used for rebuilding but it lacks information on the optimal time horizon or time path. Because static models exclude information on the transition, and the reasons behind the need for rebuilding, they will be inadequate for addressing the rebuilding of fisheries (Clark, 2006a).

Bioeconomic analysis for rebuilding requires an examination of how key parameters affect the optimal time horizon and time path as stock levels increase. How parameters affect the static equilibrium (e.g. Table 1) can be quite different from how they impact the dynamics of a time path. And, while constant parameters may be acceptable for determining an initial equilibrium target (e.g. MEY), the dynamic specification may need to consider endogenous effects such as how costs vary with stock size or effort or how fish prices may change with harvest levels or fish size. For long lived stocks, bioeconomic models may need to include the age structure of the population. This would be especially critical if there was concern over the abundance of older females that could disproportionately affect successful rebuilding as opposed to modelling the overall size of the biomass. Cohort-based bioeconomic models would also be important where the unit value of an individual can vary by age which in turn can affect the optimal allocation of stock among heterogeneous harvest groups that use different gear, fish in different areas, or produce different products (e.g. Armstrong and Sumaila, 2000; Larkin and Sylvia, 2004 Recent advances in the theory of bioeconomic models for age-structured populations (e.g. Tahvonen, 2009) are likely to inspire more empirical research of such populations.

Investigation of the use of bioeconomic models for UK fisheries (regardless of the status of the stock or fishery) show substantial increases in economic profit from a potential change in the management regime. This is because bioeconomic models can examine how the revenues and costs the profit potential of the fishery would change under different allocation strategies (Whitmarsh et al., 2000). The importance of this information cannot be overstated.

\section{How does bioeconomic modelling relate to management strategy evaluation (MSE)?}

Bioeconomic models specify an objective function to be maximized or minimized, which is used to determine the corresponding "optimal" management strategy. Management strategy evaluation (MSE), on the other hand, "involves assessing the consequences of a range of management strategies or options and presenting the results in a way which lays bare the tradeoffs in performance across a range of management 
objectives $(\ldots)$ it seeks to provide the decision maker with the information on which to base a rational decision, given their own objectives, preferences, and attitudes to risk." (B. Fulton, Presentation on MSE Tools, November 12, 2008).

The specification and use of an MSE paradigm is to adopt a specific adaptive management strategy, which means the use of an iterative process of optimal decision making in the face of uncertainty (Holland and Herrera, 2009). MSE involves a detailed network of biological modelling, management prescriptions, and mechanisms for stakeholder input. MSE frameworks are often described with elaborate flow charts that identify how and when information is used such that all biologists, managers and stakeholders are aware of when certain types of a regulation should be changed. More specifically, these flow charts are characterized as continuous loops with no identifiable beginning or end. This type of specification highlights the continual flow and evaluation of new information that can be used to modify management plans. In short, it is an adaptive management cycle with planning, implementation, evaluation and adjusting activities. Within this general framework which is inherently sequential and not simultaneous it is relatively straightforward to calculate changes in landings, revenues, and costs. This information could be useful to commercial sector stakeholders and managers but does little to capture the role of economic information in affecting catch and processing strategies.

An example of an MSE management loop is one that contains the development of a biological model that predicts the status and surplus production available from the stock, which is then used in a management sub-model (with stakeholder input) to develop specific management plans (i.e. allowable effort and or harvest levels, and allocation by stakeholder group if relevant). Then the fishery is monitored to obtain estimates of the management control variables and stock indicators that can be used to refine the biological model and or to solicit stakeholder input that is used to re-estimate the assessment models, to determine new estimates of stock status, and then new management plans if necessary. For example, the TEMAS (technical management measures) software simulates the short- and long-run dynamic effects of fleet behaviour within the MSE framework to operationalise multi-species and multi-fleet bioeconomic modelling (Ulrich et al. 2007). A comprehensive example of how the approach can be applied empirically is that by Dichmont et al. (2008) who applied the technique to the Northern Prawn Fishery in Australia and explicitly examined the bioeconomic MEY solution.

Inclusion of bioeconomics into the MSE framework can be parallel or simultaneous to the biological determination of surplus production levels. The addition of a bioeconomic model is beneficial to this process since MSE is often used as a tool to assess the consequences of alternative management choices and or fishery objectives, which is precisely the strength of bioeconomic modelling when used as a simulation tool. While bioeconomic models include an objective function, they do not have to be optimized and used as a prescriptive tool. The use of bioeconomic models as a descriptive device allows for the examination of economic tradeoffs, including the estimation of potential profits. The fact that bioeconomic models entail the specification of an objective function (which can be a multi-objective function) can force diverse stakeholder groups to be transparent in their objectives and performance indicators. The identification of performance indicators is critical because it can provide additional metrics to be tracked during the ongoing collection of data on the fishery for monitoring and evaluation. Lastly, given there are at least two distinct underlying objectives associated with rebuilding (i.e. to increase stock size and or improve the economic conditions of the fishery), the 
MSE with a bioeconomic model is well-suited to customizing and prioritizing the indicators within the adaptive management framework.

\section{Use of bioeconomic models to address fallacies in rebuilding fisheries}

There is worldwide concern for the sustainability of marine fisheries and commercial fisheries in particular (e.g. Hilborn et al., 2005; Worm et al., 2009). Some international organizations and countries have revised management plans and established specific protocols for addressing the need to rebuild fisheries (Khwaja and Cox, 2009). One tool used to manage and rebuild fish stocks is calculation of reference points which associate specific harvest management rules with different levels of the stock. While these technical rules are intuitively appealing they ignore ignores fishers' behaviour and economic conditions of the fisheries (Hilborn, 2002; Clark, 2006b). Management based on standardized reference points and global rules may also ignore the biological realities of local contexts. Reference points often discourage innovation and the development of better management alternatives (Hilborn, 2002). While reference point-based management might result in stock recovery, the process is often characterized by an inability to assess success or failure in achieving fishery goals beyond those established for the stock. A focus on predetermined biological-based rules limits creative options within a broader economic and social context.

There is a larger question behind the choice of management strategies and tools regarding the ultimate purpose of fisheries and the parameters to be used for rebuilding. Hilborn (2002) points out that emphasizing the precautionary principle has caused neglect of the true purpose of a fishery, which is "to produce social and economic benefits to society." Stock conservation (i.e. sustainable harvest levels) and maximization of social benefits over time from a fishery are not mutually exclusive goals; they are, by necessity, compatible and complementary. Full social benefits from a fishery are not realized when the fish stock is "over-exploited" since by definition population is below the level that produces MEY. Conversely, recovery of an over-exploited fish stock cannot take place if economic and social realities are ignored.

Clark (2006a) identified five paradigms associated with the misunderstanding of bioeconomic modelling in fisheries and used these to discuss future fishery management problems. The following section builds on these paradigms by extending their focus to the use of bioeconomic models for rebuilding fisheries. In total we discuss five commonly held misconceptions regarding rebuilding in general and how the use of bioeconomics can help to better assess the implications of rebuilding for a given fishery.

\section{Paradigm 1: Fishery closures are the "maximizing” approach to successful rebuilding}

Once a stock is declared "overfished", it is tempting to consider the most direct, enforceable, and effective solution to rebuild a stock: close fisheries. In fact, many studies advocate closure as a solution to what is considered to be an urgent problem (Safina et al., 2005; Sumaila and Suatoni, 2005; Rosenberg et al., 2006; Gates, 2009). Many studies claim that expedient rebuilding is the benefit-maximizing rebuilding strategy in the long run (Hilborn et al., 2005): the sooner we close, the sooner we open, so benefits are realized sooner. Rosenberg et al. (2006) reiterate the relevance of this approach by claiming that "the overall [negative] economic impact [from keeping fisheries open] is 
likely much greater as a result of a long continued decline and delay in rebuilding than from a short-term reduction in catch in order to rebuild populations quickly (p. 308)."

In addition to the appeal of a simple approach, a common justification for rebuilding as soon as possible is solely because it is biologically possible within a reasonable time frame. Referring to stocks in the United States, Rosenberg et al. (2006) states that: "most stocks have the potential to be rebuilt within 10 years (Safina et al., 2005), so this lack of demonstrable progress is disappointing (p. 305)."

According to Caddy and Agnew (2004), leaving fisheries open during rebuilding is "impractical" and will not generate sufficient financial returns. The authors, in reviewing rebuilding attempts worldwide, do, however, acknowledge that "the collapse of Canadian groundfish stocks made closure inevitable, but revealed that this measure is not inevitably successful (p. 1)." The study by Caddy and Agnew advocated for closure, but did not examine rebuilding within a broader bioeconomic context. Over 60 considerations are listed in developing a rebuilding plan but these are primarily based on seven cases studies. None of these cases acknowledge economic behaviour or whether economic, social, community and cultural concerns are relevant.

While the literature advocating closures contains intuitive appeal, intuition is often the only reason (other than a supportive legal environment) provided to justify a closure. The quantitative analyses that have been used to support the quickest possible rebuilding horizon (e.g. Sumaila and Suatoni, 2005, or Gates, 2009) utilize simplistic financial analysis with flawed assumptions. ${ }^{3}$ In fact, we could not find any studies that conducted an economic analysis that explicitly considered or supported a closure (i.e. considered both the benefits and costs). That said, there is a paucity of studies that have supported the continuation of fishing using a model that accounts for the salient social and economic factors for any given fishery. ${ }^{4}$ In summary, delaying the rebuilding horizon in order to allow for some level of harvesting can provide the following benefits:

- Continued data collection, especially on the stock that can be used to monitor the recovery (i.e. a "sentinel" fishery).

- Support for the sustainability of coastal communities.

- Retain expertise in harvest and processing.

- Retain malleable capital, including labour, in the harvest and or processing sectors.

- Maintain markets at the local level versus a loss of the market to imports.

- Provides higher product prices initially for distinct products and higher yields later on as the average size of individuals increases.

- Reduce harvesting costs as the stock size grows.

3. First, costs are assumed to be lower during rebuilding despite significant increases in landings. Second, the increased landings from rebuilding are compared to perpetually low "status quo" levels; a more appropriate comparison is with an alternative (i.e. slower) rebuilding horizon, which is more likely than operating at unsustainable levels in perpetuity. Third, catch is assumed to increase beginning in the initial year of the closure rendering the results invalid for addressing closures.

4. This lack of available information is likely due to the empirical nature of the research. Such studies would have been conducted for fisheries managers and not peer-reviewed outlets. 
- Positive discount rates increase the relative value of harvests early in the rebuilding horizon.

- Prevent the need for higher government expenditures overall for (1) subsidies to existing stakeholders that would be put out of business or (2) a legal defence from lawsuits that might challenge the closures.

- Continued anthropocentric use of the resource, which is fundamental to justify any stock management activities.

The notion that generalizations regarding effective building strategies (e.g. automatic closures) may not be optimal to rebuild fisheries are also supported by recent evidence regarding the success of rights-based management systems (Costello et al., 2008). The overall results claim that individual transferable quota (ITQ) fisheries are significantly less prone to collapse than non-ITQ fisheries. Thus, the role of the institutions in rebuilding and sustaining a viable fishery is paramount. Any rebuilding strategy must assure that the same mistakes are not repeated, which often involves capacity reduction programs or a change in institutional structure (Whitmarsh et al., 2000). Arguments for the development of institutional systems that account for the incentives of fishermen were, for example, summarized by Hilborn et al. (2005) and were noted by Rosenberg et al. (2006).

$\rightarrow$ Closures are not likely to be benefit-maximizing nor are they guaranteed to rebuild fisheries. Empirical analysis of support for closures needs to consider all elements of the fishery, especially changes in fishing effort and costs that will affect rebuilding.

\section{Paradigm 2: A target stock level needs to be determined before economic considerations are addressed}

Many rebuilding efforts focus on first estimating a pre-determined biological rebuilding target, and then examining how to achieve it. This approach is often mandatory (e.g. in the United States this approach is based on the current interpretation of national standards) but is inconsistent with the premise of managing and sustaining a fishery over time. This is because the MSY may not be economically sustainable and, therefore, will not stabilize a fishery or a community (as discussed earlier). The determination of a target stock level based on the sustainable yield curve only considers historic effort, which is not absent of economics. If economics are of concern, then the benefits and costs should be considered appropriately. ${ }^{5}$ However, the assumption that economics is a tool to be used only after a rebuilding target has been determined, or after any imbalances between stock size and fishing capacity have been resolved, is pervasive (e.g. Penas, 2007; Khwaja and Cox, 2009).

Identifying a target MSY level for rebuilding is challenging, even when economic conditions are stable. The MSY is a long-run concept, but it is one that will change with deviation in any number of factors including biological parameters (such as caused by changes in the ecosystem), the level of effort devoted to fishing, or the relationship between the stock and the harvest level. For example, if general economic conditions change, or technology changes, then effort devoted to fishing might change (Whitmarsh et al., 2000). There are countless other examples of exogenous factors that can affect

5. It is the rare exception that a stock is deemed in need of rebuilding on a purely biological basis. To our knowledge, no studies exist that support rebuilding due to high existence values for a commercially valuable stock. If there is such a stock, then no modelling would be needed. 
fishing mortality and, thus, the estimation of MSY, or change the MSY during the rebuilding process. These changes are realistic but are not considered under a protocol that requires the establishment of a target to be used for at least a decade in the United States Moreover, "experience suggests that successful recovery depends more on management infrastructure and socio-economic context than on stock calculations alone, whose accuracy has often been overestimated" (Caddy and Agnew, 2004). Given the imprecise nature of the MSY (and by extension the reference points used to examine the underlying stock level) and that it has, at best, played a supporting role in previous successful recoveries, it is curious that its use as an absolute target continues.

The establishment of an MSY target that is higher than current stock levels provides an indication of the future productivity of the resource, which is an effective way to communicate that management can improve a fishery. According to Munro (2009), however, although the future productivity of a resource is the "necessary incentive" for sustainable fisheries and rebuilding, what is often overlooked is that the timing of harvest is crucial and could be more important than the size of the stock. More specifically, Wiedenmann and Mangel (2006) found that a suboptimal age distribution may occur even if MSY level achieved. Larkin and Sylvia (1999) provided an early example of how changing the timing of harvest during the season had a long run positive impact on yield and stock size for a mid-water hake species managed with an annual quota. By allowing harvest later in the season, after fish had a chance to recover from spawning and migration, the fleet could harvest fewer but larger individuals. In addition to the stock effect from harvesting fewer fish and changing the age structure to have more and larger (older) fish, there was also a positive effect on the value of the resource since fish could be used to produce different, higher-valued products with higher recovery rates. Homans and Wilen (2005) modelled the potential market effects from altering harvest schedules and their affect on "optimal" management without compromising the stock. ${ }^{6}$ These examples are intended to highlight the foregone potential of a fishery when target stock size is determined initially and in isolation when, in fact, it could be considered an endogenous policy variable.

$\rightarrow$ Setting the MSY first ignores the fact that it is based on assumptions regarding economic factors. Target stock levels should be determined with the optimal exploitation rate and horizon, not initially and independently.

\section{Paradigm 3: An MSY target will provide sufficient stock to sustain a fishery}

The finding that the MSY can be a solution where profits are zero or negative means that an MSY target may not be sustainable from a community (i.e. fishery) perspective (Kompas et al., 2009). While this finding should be sufficient to question the potential effectiveness of using MSY as a management target, it remains in use for rebuilding stocks. For example, "the traditional assumption of Alaskan fisheries management has been that if the resource was managed to produce maximum sustainable yield [MSY], the economics would take care of itself" (Bue et al., 2008, p. 692). Using a detailed bioeconomic model of the Pacific salmon fishery, with multiple fleets and markets and stochastic dynamics, the authors show that benefits are maximized by harvesting at a

6. If there is concern that an economic analysis will recommend a lower sustainable stock level (whether that concern is valid is another issue), then readers are reminded of the work of Grafton et al. (2007) who show that stock levels from bioeconomic models are likely to be higher than MSY stock levels. 
stock level that is below that used to generate the MSY. While Grafton et al. (2007) have shown that the size of the biomass associated with MSY compared to MEY depends, in part, on the growth rate of the species - and not traditional economic factors such as prices, costs, or discount rates - it is the possibility that the benefit-maximizing harvest could result in a stock level below MSY that prompts the most opposition. It is a good policy question to explore the potential risks to a sustainable fishery from the pursuit of the MSY.

Returning to the distinction between a stock recovery and a rebuilt fishery, Ward and Kelly (2009) provide additional insights to emphasize the risk in assuming the MSY will sustain a fishery. According to Ward and Kelly (2009):

"Simple biologically based stock assessments, even if accurate, are not a good metric of success or failure because [United States fishery] managers have so many objectives that have to be balanced in the management process. Stock size can be increased to improve economic efficiency, or the economic viability of the fishing industry... Alternatively, stock size can be improved by increasing the harvest cost until some arbitrary, precautionary MSY is achieved which is detrimental to the fishing industry and the communities dependent on it. While both points are acceptable from a biological perspective, only the MEY stock size is consistent with economic and social objectives facing managers and the legal requirements under the law" (p. 170).

Aside from the issue of a target stock size, the importance of a 'viable recovery path' that explicitly recognizes the financial sustainability of the commercial fleet has been recognized as a critical factor to a successful rebuild (e.g. Martinet et al., 2007; Martell and Walters, 2008). This is an important realization since, as Caddy and Agnew (2004) identified, "it is usually supposed that a return to a 'normal' exploitation strategy will follow once the recovery 'target' has been achieved, but experience shows that growing disputes over stock status between stakeholders occur as some recovery becomes evident" (p. 100-101). So, while it is true that the "net benefits" defined strictly as socioeconomic objectives may not be the only factor important to rebuilding, it is rare that the costs or benefits associated with managing for an MSY target do not matter at all. The converse is also true; fisheries managers and society as a whole should not consider biological or ecological factors as the sole determinants in evaluating the effectiveness of a rebuilt fishery.

$\rightarrow$ The MSY has been shown to be unsustainable under a variety of plausible conditions, thus, using MSY as the target stock level is not a necessary condition to ensure the viability of a single stock fishery.

\section{Paradigm 4: Bioeconomic analyses are too complex or contentious for policy use}

Bioeconomic models can require substantial amounts of data and sophisticated solution techniques, especially when considering stochastic information on biological and economic parameters (e.g. Smith, 2008). While applied bioeconomic models increase the scope of data needs, the type of bioeconomic model will dictate the level of data needed. Simple surplus production models can be used with the price of fish and the costs of fishing (e.g. as estimated from a harvester survey) to determine the maximum economic yield (MEY) (e.g. Milon et al., 1999). Fisheries that are characterized by distinct cohorts may, on the other hand, need price and yield information by age or size and seasonal data if costs or demand varies by week or month (e.g. Larkin and Sylvia, 1999). Incorporating the behaviour of harvesters adds additional complexity and data requirements. Data needs vary directly with the complexity and realism of the bioeconomic models. 
With respect to rebuilding, bioeconomic models use biological and economic information to evaluate alternative rebuilding targets and approach paths. However, this use of 'economics' as a tool is often confused with financial analysis; namely, short-run policy that is justified by socio-economic concerns that run counter to biological recommendations regarding the stock (Aps et al., 2007). But the strength in bioeconomic modelling is that it captures the behaviour of fishermen with respect to their response to profits, which allows for a suite of policy-relevant analysis (Whitmarsh et al. 2000; CEMARE, 2009). Bioeconomic analysis or economic analysis is not synonymous with generating values associated with pre-defined harvest plans. It is perhaps the possibility that policy recommendations may differ between biological and bioeconomic analysis, or that the bioeconomic analysis will identify winners, losers, or the role of special interest groups, that can cause bioeconomic analysis to be considered contentious and, therefore, too costly or time consuming.

Another confusion related to the use of economics is the nature of the results. Bioeconomic models are descriptive representations of a fishery that identify a course of action that is consistent with the goal(s) of managers. Bioeconomic models can, therefore, be used to examine proposed alternative objectives and actions. When used as an optimization tool, a bioeconomic model will identify the "optimal" management plan associated with the principle objective. This "optimum" is not synonymous with what should be implemented in a given fishery. This distinction is highlighted in the following passage by Frost and Andersen (2006):

"although bioeconomic analyses emphasize the problem inherent in the exploitation of fish resources, namely the dissipation of the resource rent, the economic analyses suffer from an inability to give indications of what should be done in complex fisheries with regard to fish stocks and fishing technology."

We would argue that what should be done is a policy issue, not the responsibility of any model or a shortcoming of any model - including bioeconomic models. For example, United States fisheries managers must consider 10 national standards in the development of fishery management plans. These standards cannot be jointly satisfied even if the biological and overall economic recommendations coincide. There are inherent tradeoffs that require policy makers to consider or prioritize all of these factors to satisfy all decision makers. ${ }^{7}$ This is where multi-objective bioeconomic models can be of most use, that is, to show the explicit tradeoffs among competing objectives and provide information to the policy process (Sylvia and Enriquez, 1994; Sylvia and Cai, 1995).

Lastly, bioeconomic studies (theoretical papers in particular) have proven successful at changing the management debate from determining the target stock level to what type of management tools account for the incentives of fishers in a way that maximizes the net benefits to society. Therefore, the use of bioeconomics has likely proved great in changing the institutions that govern fisheries worldwide (R. Hannesson, R. Arnason, pers. comm., 23-24 November 2009), but whether such systems are universally beneficial (despite the bioeconomic evidence) remains a subject of debate.

$\rightarrow$ Bioeconomic models can be complex and contentious since they often compare stakeholders and highlight the importance of the management system, including the

7. It is most common to have management decisions made by a committee or a team and not any one individual. 
need to define objectives and benefits and consider alternative systems that can achieve them.

\section{Paradigm 5: Bioeconomic models are useless if they suggest unrealistic changes to fisheries}

Deterministic bioeconomic models can produce point estimates of sustainable harvest levels or the exploitation path that will maximize the economic benefits derived from the stocks. In the case of overfished stocks, these optimums may differ significantly from the status quo. While significant changes to a fishery may appear daunting, they serve to highlight potential resource rents and the importance of having explicit management objectives.

Bioeconomic models can also incorporate stochasticity into the determination of the "optimal" rebuilding plan. The biological and economic relationships in stochastic specifications are usually non-linear and dynamic and have the features of any dynamic system, including phase shifts and threshold effects. As a result, the benefits and costs are not proportional to biological management or harvests such that a change in any one variable is not likely to have a linear effect on the optimal solution; that is, the results are not scalable. As such, several bioeconomic studies caution that adjusting the harvest or effort levels predicted by the models can compromise the ability of the fishery to reach the desired solution (Milon et al., 1999; Kompas and Che, 2004). The implementation of a policy that is not supported directly by the models can lead to an unfounded discrediting of the bioeconomic approach as the industry fails to improve. Conversely, "with uncertainty taken into account, it is not unreasonable to approach an estimated target in a slow way, with adaptive management responses to changes in prices, costs and the underlying biology of the fishery" (Kompas et al., 2009, p. 14).

Despite the potential for ad hoc adjustments to bioeconomic modelling results for policy purposes, it is important to emphasize the ongoing role that bioeconomic modelling can provide to the management process. In practice, the use of bioeconomics is most appropriately considered one tool of many that managers need to consider in making decisions (Rettig, 1987). It is an avenue to get fishermen involved in the management process by highlighting the need for, and importance of, good economic data. Over time, the fishermen will see the potential and begin to trust the tool. Such involvement could also lead to improved data collection as fishermen realize that any misrepresentations in the data could result in an incorrect management plan.

$\rightarrow$ Bioeconomic results are not scalable but partial adoption of the results can form the basis for adaptive management within an MSE framework and increase stakeholder participation.

\section{Bioeconomic models for rebuilding fisheries: applications}

\section{Fishery Selection Criteria}

We sought to identify several geographically-distinct empirical bioeconomic studies on fisheries where the results have been used to help define future management plans. This has been a challenge for three reasons: (1) many rebuilding mandates use biological criteria as the primary rebuilding targets; (2) rebuilding plans are often implemented within tight time constraints that precludes the completion of bioeconomic studies designed to formally evaluate policy options prior to implementation; and, 
(3) bioeconomic models developed for implementing policy are written for policy makers rather than analysts or academics and may not be readily available for a broader audience.

Theoretical and stylized bioeconomic models are well-suited for evaluating rebuilding in general, and many have been published in peer-reviewed journals. Academic journals have also published a relatively large body of literature on empirical bioeconomic models of specific fisheries, but most are typically conducted for the ex-post evaluation of biologically-based management plans. At this time, there is a growing body of literature that uses retrospective analysis as a means of introducing the role of economics into dynamic fisheries management. Retrospective studies are intentionally postimplementation and have primarily focused on simulating forgone revenues or profits versus optimizing to find a solution to direct the future management of a fishery (e.g. Marsden et al., 2009).

In the following section, five fisheries are reviewed. These fisheries represent the two dominant rebuilding goals: rebuilding to increase stock size or rebuilding to improve returns from fishing. The first type (stock rebuilding) is a fishery where low stock levels compromise the existence of the stock and the fishery. The second type (fishery rebuilding) is where the economics of the fishery have produced tremendous hardship such that although the stock level is sufficient from a biological perspective, management action is needed to improve the profitability of fishing. With respect to the use of bioeconomic modelling, there are three types of examples: those that have used the results of a bioeconomic model to guide the rebuild, those where bioeconomic models were applied for the purpose of directing the rebuild but the recommendations were not followed, and those where bioeconomic models were applied but the recommendations were implemented partially or implemented gradually over time. These cases collectively provide useful examples of both the type of information that can be generated and, perhaps more importantly, highlight how the information can provide valuable lessons on the challenges of implementation.

\section{Case Studies}

\section{United States Striped Bass}

Situation: The Atlantic States Marine Fisheries Commissions' Committee on Economics and Social Sciences convened a workshop to explore the use of a spreadsheetbased bioeconomic model for rebuilding the striped bass stock. Due to insufficient data, actual and hypothetical data were used to explore rebuilding alternatives beginning with an overfished stock. Due to the use of hypothetical data, results were intended only to showcase the use of bioeconomic models in future management decisions using annual days fished as the control variable. Several scenarios were examined to achieve a specified spawning biomass goal including the status quo, closed seasons for the commercial or recreational sector, and different harvest levels. The model was used for simulations only in this workshop. The economic values generated by each scenario where then compared along with the rebuilding path for the stock.

Modelling approach: An age-structured (12 cohort) biological model was developed using an initial stock size and age composition, empirical recruitment and growth functions, an assumed age at maturity, natural mortality rates and catchability coefficients (Anderson, 2002). To incorporate the economic submodel, the initial number of fishing participants had to be specified (commercial vessels and recreational harvesters). The economic submodel for the two commercial sectors required data on fish prices, fixed 
costs, and variable cost functions in order to calculate profits, which are collectively referred to as producer surplus if measures of opportunity costs are used. For the recreational sector, a willingness-to-pay function was specified whereby the economic value of each fish caught for recreational purposes varied with the catch rate, minimum size, and days fished. This function was needed in order to determine the consumer surplus associated with recreational fishing, which is the appropriate measure of value since it is the value above the cost to harvest. Lastly, a discount rate was needed to calculate the net present value of each scenario in order to facilitate comparisons of alternative rebuilding plans that had distinct effects on each stakeholder group. With this modelling approach, changing stock size and composition affects the profitability of the commercial fleet (producer surplus) and the welfare of recreational harvesters (consumer surplus), with implications for fishing effort in the subsequent year, with further effects on the stock size. This is the behavioural dynamics that economic modelling can capture.

Lessons: Benefits were found to vary by year and sector. The most effective strategy involved closed seasons that differed across sectors (with the commercial sectors losing the most fishing days). Workshop attendees recommended that biological expertise be consulted for the specification of the biological dynamics component to ensure that the salient features of the stock for rebuilding are incorporated. Similarly, economic expertise should be required for the calculation of the producer surplus for the commercial sector and consumer surplus for the recreational sector. Ideally, the stock assessment and bioeconomic models would be developed in tandem so data issues (availability, quality, and needs) could be addressed simultaneously and any discrepancies or inconsistencies in the model specifications reconciled.

\section{Canadian North Atlantic Cod}

Situation: A two-year moratorium was implemented on one of the four major North Atlantic cod stocks in 1992. The closure eliminated directed landings that had been at 200000 tonnes annually. The closure was needed due to stock declines from successive years of high fishing mortality and weak recruitment (causing fewer harvestable age classes, lower weights at age, and increasing maturity at age). Lane and Palsson (1996) developed a bioeconomic model to evaluate a continued moratorium versus a 'sentinel fishery' whereby fisheries would remain open at approximately $20 \%$ of pre-closure landings levels. In addition to exploring the potential for a sentinel fishery to retain data collection on the stock, the bioeconomic model was used to examine the managerial effect of uncertainly in the underlying population parameters. This exercise was considered critical since historical population modelling (virtual population analysis in particular) had predicted dramatically different estimates of stock size and fishing mortality in successive stock assessments.

Modelling approach: An age-structured bioeconomic model of the commercial fishing sector was originally developed by Lane and Kaufmann (1993). This model was updated and used to examine alternative harvest paths, including a closure. The model was also used to conduct a thorough sensitivity analysis of the assumed rate of natural mortality, stock-recruitment relationship, initial population age structure, weight-at-age, and unit prices and costs associated with harvesting cod. The model simulated the 1989 to 2001 planning horizon.

Lessons: The controlled exploitation strategy would have doubled employment and earned income as compared to the moratorium, which resulted in the harvest of approximately 20,000 tonnes as bycatch. Most importantly for the stock, the sentinel 
fishery would not compromise rebuilding. Aside from the additional value of harvests allowed from a sentinel fishery, several other benefits of allowing a small level of commercial harvest could not be estimated and were not included. The excluded benefits included reduced transfer payments to commercial fishing enterprises, the value of maintaining a market presence, and the value of maintaining harvesting and processing expertise. These potential benefits imply that maintaining a directed commercial fishery also retains labour and capital in fishing that, if highly malleable, could be costly to return due to 'sticky' capital and labour market adjustments.

\section{Australian Northern Prawns}

Situation: Management of the Northern Prawn Fishery (NPF) falls under the jurisdiction of the Australian Fisheries Management Authority (AFMA), which is advised by the local Northern Prawn Fishery Management Advisory Committee (NORMAC). In 2003, the NPF was experiencing an economic downturn so NORMAC convened a special meeting to obtain economic advice and consider potential solutions. Although several economic and bioeconomic studies had been conducted on the fishery in the preceding decade (Dann and Pascoe, 1994; Kompas and Che, 2004, and references cited therein), the explicit consideration of economic issues was new to NORMAC (Richey, 2004). The previous studies generally found that fishing effort (i.e. the number of licensed vessels operating in the fishery) exceeded the levels at which maximum economic yield (MEY) could be achieved.

Modelling approach: An annual model was specified that accounted for three distinct prawn stocks (brown tiger, grooved tiger, and endeavour), each with its own stockrecruitment relationship (Kompas et al., 2009). A 50-year time horizon was used. Three vessel size categories were modelled. Prawn price was assumed to depend on quality grade and year. Uncertainty in the biological relationships, catch rates, fishing power, and prawn prices was also considered. The model predicted fleet size and fishing days in addition to the MEY. The model was optimized with and without discounting.

Lessons: Several lessons resulted from the body of work on the NPF. First, "designating the fishery as 'overfished' or not depends on the chosen discount rate; a high rate may imply small (but still optimal) stocks" (Kompas and Che, 2004, p. 3). Second, the findings of the bioeconomic studies generally concluded "that stocks are well below economically efficient levels" (Kompas et al., 2009, p. 1). Based on the bioeconomic model results, NORMAC formally adopted MEY as a target reference point. Third, adoption of the target would require a 30\% reduction of effort, but the industry would have to agree before AFMA could implement this new target so the members compromised on a $25 \%$ gear reduction. In order to prevent concerns of effort creep and substitution, additional recommendations were passed. The compromise, while not supported by the bioeconomic analysis, was a key step toward incorporating an industry advisory committee and developing trust and confidence in the models and the managers. Fourth, the NPF studies have shown that the input controls used in the fishery have had unintended negative effects. The gear restrictions, for instance, decreased the technical efficiency of the fleet, thereby increasing the costs of fishing and consequently lowering the profitability of the fleet. The uncertainty associated with input restrictions may have also been greater than that associated with output restrictions, such as the levels of total allowable catch (TAC) (Kompas and Che, 2004). In light of these conclusions, AFMA decided to change its management strategy from input to output controls. The fishery is expected to be managed using TACs and individual transferable quotas (ITQs) by 2010 . Finally, the effect of these studies on fisheries policy in Australia has become evident in 
recent years. The restructuring of AFMA's objectives in 2005 was accompanied with a buy-back program specifically intended to reduce the number of vessels operating in the NPF by directly purchasing vessel and gear fishing rights (Rayns, 2007). Gooday et al. (2009) give an overview of cases where the lessons learned in this fishery are being applied in fisheries throughout Australia.

\section{United States Spiny Lobster}

Situation: In the early 1990s an individual transferrable rights program was implemented in the United States spiny lobster fishery in an attempt to improve profitability (i.e. rebuild the fishery). The main gear type is a wooden trap that is standardized by regulation. The number of traps had increased dramatically over time. The rights-based system was based on effort, the total number of commercial traps in particular. Trap certificates (where each allowed the use of one trap per season) were allocated based on past landings and reported trap use. In the first three years of the program, traps were reduced by $10 \%$ each year. Trap reductions were stopped after protest from fishermen that the program was not working even though a quantitative objective was never specified.

Modelling approach: A bioeconomic model was developed to estimate the MEY harvest and associated optimal number of traps that managers could use to justify future trap reductions (Milon et al., 1999). In other words, this analysis attempted to estimate the static, or long-run, equilibrium conditions in the fishery. This was accomplished by estimating several alternative surplus production models and cost functions to consider the observed heterogeneity and to provide a range of plausible outcomes. The estimation of surplus production models required a time-series of catch and effort data. The cost functions required trip and vessel level data from logbooks and surveys to obtain the fixed and variable costs for the most recent year for a representative sample of the fleet. To obtain the MEY solutions, information was needed on the dockside price of lobster. To obtain an estimate of the net present value of each effort unit, an assumed discount rate was also needed. Marginal benefit and marginal cost curves where used to identify the optimal level of effort under each set of assumptions.

Lessons: The best fitting surplus production model was an exponential functional form which implies that catch reaches a maximum level that is unaffected by the addition of effort. This specification implies that effort reductions will only benefit the fishery once a threshold level is reached. Results indicated that the MEY level of effort (i.e. total number of commercial traps) in every scenario was well-below the current level of effort. Fishermen were upset that additional effort reductions might be recommended given that they had not observed benefits from previous reductions. Most likely, the benefits were eroded due to latent effort and unstrained non-trap and recreational effort. Given that the fishery was still in need of rebuilding, "passive reductions" 8 were implemented and the moratorium on active reductions was resumed in 2005 with a target established at the estimated threshold level identified in the surplus production modelling. These changes reduced one aspect of uncertainty, namely, the point at which the state would discontinue reductions. Reducing uncertainly is likely to increase the value of the fishery and vice verse. The level of the target and continued use of small active reductions is an example

8. Passive reductions eliminate effort only when it is transferred. In this program, fishermen own and trade (buy or sell) certificates that allow the use of each trap. During a passive reduction, the number of certificates a buyer receives is reduced upon transfer. This is in contrast to "active reductions" that eliminate an equal percentage of certificates of each owner. 
of policy compromise and highlights the potential role of estimating the optimal effort reduction path with a bioeconomic model. This is critical since small annual reductions can require fishermen to continually participate in the transfer market, which is inefficient since individuals are required to find their own trading partner. The costs of transactions could be considered in the decision of how fast to reach the target. Finally, this program only constrains one type of commercial gear and ignores other commercial fishing effort (e.g. diving) and all recreational effort, which has increased dramatically since the program was implemented. All stakeholder groups should be explicitly modelled because unconstrained effort can compromise any attempt to improve the sustainability of the overall fishery.

\section{Norwegian Spring Spawning Herring}

Situation: During the past five decades the Norwegian spring spawning herring (NSSH) stock has been most accurately depicted by a "U" shaped curve. After suffering a near collapse during the 1970s and beginning of the 1980s, fishing in several areas for immature (i.e. smaller) fish and fishing for commercial purposes was banned. In addition to stock size, the age composition was of primary concern in this case since younger fish have continued to comprise the majority of the landings, with implications for long-term stock recovery.

Modelling approach: An age-structured dynamic bioeconomic model was developed to simulate alternative management measures and their effect on the optimal exploitation pattern and rate (Sandberg 2005). A 10-year horizon was used to compare at least three performance indicators: net present value, spawning stock biomass, and the probability that the stock will be above the minimum acceptable biological level. Unit prices and harvesting costs were used to calculate profits, which were discounted using a positive discount rate. Fixed costs were excluded, which is standard treatment for "sunk costs" that should not affect future economic decisions.

Lessons: Results indicated an indirect relationship between the net present value and spawning stock biomass (Sandberg, 2009). While increasing the biomass reduced the economic returns, the model also showed how keeping open a minor fishery during the rebuild provided higher than proportional earnings due to a market effect of having scarce supplies. The fact that this pelagic species is characterized by schooling behaviour has implications for the cost structure (i.e. since costs to harvest remained unchanged, these costs should not be used as an indicator of catch rates for the purpose of assessing stock status). Costs may also be under- or over-estimated due to stock effects associated with searching. For example, harvest costs will not change as pelagic stocks decline. Lastly, some species can be critical to the health of the ecosystems such that the value of rebuilding may be underestimated if the model relies solely on commercial market values. Thus, the value of ecosystem services provided by the food web could impact the optimal rebuilding plan. 


\section{Complications of empirical bioeconomic modelling}

The case studies examined here provided a number of examples of how modelling must first distinguish the salient aspects of the fishery. Defining what needs to be included, including the definition of the fishery itself, is often the most difficult and perhaps time consuming task of the analysis. The complexity of modelling fisheries may be distinctly on the biological or economic components, or both. This is an important distinction to make. Specific complications for developing a bioeconomic model of a fishery to be used by managers include:

- Modelling a single stock may be straightforward from a biological perspective but complicated by the presence of several distinct stakeholder groups, each with their own set of economic characteristics which may be poorly understood due to the lack of data. Even studies that advocate for rebuilding as fast as possible acknowledge that there are "complications" in individual fisheries (e.g. Rosenberg et al., 2006).

- Considering multiple objectives (including those that define the ecosystem to contain the net benefits of market and non-market economic values to humans), may reveal that it is biologically impossible or prohibitively costly to rebuild all species to the MSY levels. This is especially true when fisheries are inter-related (De Young et al., 2008; Stope, 2008). For example, a previously sustainable fishery may experience an expected increase in effort as fishermen who were previously targeting the protected species switch their effort to target other species. When attempting to rebuild a specific stock within a specific timeframe, conflicting objectives and entry and exit decisions of fishermen may be critical. In the case of United States fisheries facing a 10-year rebuilding horizon, Safina et al. (2005), concedes that the inflexible horizon does "not address the need to reduce unwanted bycatch or to maintain ample quantities of prey, rare species, high-quality and refuge habitats, and other ecosystem concerns" (p. 708).

- The purpose and use of closed areas can affect the specification and estimation of the benefits associated with eliminating fishing effort in the region, which must be balanced against the biological costs of concentrating future fishing effort around the boundaries. This is because fishermen are likely to change their behaviour once an area is closed for fishing (Kahui and Alexander, 2008). The examination of closed areas (such as marine protected areas or MPAs) with respect to a reallocation of effort is just one example of where fleet dynamics should be considered within a spatial bioeconomic framework. See Holland (2000), Smith and Wilen (2003) and Sanchirico (2005), for more on spatial bioeconomics and effort redistribution and Merino et al. (2007) for more on effort dynamics, particularly with respect to whether harvesters cooperate.

- Bioeconomic models require information on product demand and harvesting cost functions to estimate the producer surplus for the commercial sector and willingnessto-pay functions to estimate consumer surplus for recreational harvesters. The accurate estimation of such functions is complicated by several factors (e.g. multispecies gear, processing activities, capital value and depreciation, opportunity costs of labour and time, substitutability of inputs and outputs, etc.). Each parameter could have a notable affect on optimal model results necessitating the need for sensitivity analysis or use of a stochastic approach. 
- Fish stocks are affected by the marine environment. In addition to changing predatorprey relationships, the temperature, salinity and oxygen levels in the marine environment can affect biological growth and reproduction and the size and quality of the harvest with implications in the market. Environmental factors that affect the market and, therefore, the welfare associated with use of marine stocks may need to be considered (Knowler, 2002).

In addition to the complexity of developing an appropriate and effective model, there are some general considerations or recommendations for the modelling that can help to facilitate implementation and use of the model. These general guidelines should help to improve the effectiveness of the modelling effort and include:

- The development of an effective and useful bioeconomic model will take time, especially considering the potential need to collect representative economic data and reconcile harvest modelling assumptions. How costs are measured and included, for example, is critical (e.g. Holland et al. 2005).

- Distinct stakeholder groups require the specification and weighting of multiple and potentially divergent management objectives. In addition, some stocks (e.g. pelagic species) may be exploited by multiple nations. Shared stocks between nations that have different management objectives, enforcement, or general economic conditions must be addressed. The examination of the role of different management objectives continues to be a primary goal of bioeconomic analysis, especially using simulations (e.g. Pascoe and Mardle, 2001; Holland et al., 2005; Deroba and Bence, 2008).

- Defining effort is complicated. Aggregate measures can include the number of homogeneous harvest units on an annual basis (e.g. vessels or people) or number of intra-season effort units (e.g. days fished, trips, hours, sets, hooks, etc.). The definition of effort in the biological and economic submodels must be compatible. For fleets that harvest multiple species, the determination of MEY is complicated by the need to allocate the joint costs of production associated with a given level of effort.

- To convince harvesters of the need to adhere to short-term harvest restrictions, the results must show that benefits from the forgone landings in the short run has a high probability of generating a future that they all will share (Munro, 2009). The equity of the sacrifices and allocation of future benefits should be addressed during the development of the rebuilding plan.

- The explicit advantages, disadvantages and implications of every management alternative and assumptions should be identified even if the effects cannot be quantified. This activity can help fishermen evaluate the alternatives and provide feedback that can be used to improve data collection. For example, the degree of capital malleability in a fishery is directly related to the political feasibility of a closure (i.e. harvest moratorium). Conversely, a closure will eliminate the benefits of having a sentinel fishery.

- The time path of harvests, prices and costs should be shown graphically consistent with the old adage that a picture is worth a thousand words. For example, rebuilding will increase costs for some stocks if effort increases in proportion to stock size but in other fisheries costs could fall due to schooling behaviour. Explaining the difference 
between costs per unit of effort and total costs, and the use of constant versus endogenous changes in unit harvesting costs is necessary. However, viewing the nature and magnitude of how the costs change can quickly facilitate the understanding among fishermen and managers and offer support for the assumptions.

\section{Summary and conclusions}

Marine fisheries worldwide have tremendous potential to generate resource rents (Arnason et al. 2008). Global arrangements to pursue some level of target fish biomass, usually MSY (e.g. UNCLOS and the Johannesburg Plan of Implementation), is recognition of that potential. Many stocks are, however, below their target level and now need to be rebuilt under international arrangements and or national laws. Bioeconomic models that consider relevant social and or economic factors can help determine both a target level and the optimal depletion or rebuilding path to get there.

Bioeconomic modelling has become prevalent in the academic and policy arenas, and results have begun to affect the management of fisheries worldwide. Perhaps the most notable accomplishments of the use of bioeconomic models to examine fisheries is the implicit effect it has had on changing the institutions that manage fisheries and the longrun effects of continuing or instituting subsidies, which are both fundamental to the examination of rebuilding.

The fishery management recommendations derived from bioeconomic models are appropriately considered as additional information to the management process and not the panacea of management reform. The most notable example is the use and comparison of the biologically-based maximum sustainable yield (MSY) and the economically-driven maximum economic yield (MEY). Even though an estimated MSY may not be sustainable if market conditions vary, the MSY target is relevant when the management objective is to rebuild the stock. The MEY target is most relevant when the management objective is to rebuild a fishery, especially one that is characterized by latent effort. In terms of modelling, these two perspectives on rebuilding lead to two distinct ways to utilize the bioeconomic modelling framework: (1) minimize the loss in resource rents of rebuilding to the MSY; or (2) maximize resource rents or any other management goal(s) by rebuilding to the MEY (Sylvia 1997, Sylvia and Enriquez 1994; Sylvia and Cai 1995). In addition, both of these approaches can employ a weighted risk framework including subjective evaluations of risk.

In order for an empirical study to affect policy, the applied research needs to be conducted in advance of any decision making and ideally as a collaborative effort between biologists, economists, and stakeholders. Given that government resources to support fisheries management are scarce, the prospect of assigning biologists additional duties to develop new and unfamiliar models will be a challenge for managers, especially when stocks are at critically low levels. Under such circumstances it may be tempting to advocate for the most direct and quickest approach to increase stock levels, which is to close the fishery. There are, however, several reasons why this approach is lacking from both a biological and economic perspective. The issue of closures is just one example of at least five that we have identified as paradigms in the management of rebuilding fisheries that can be addressed with a bioeconomic modelling approach: 
- Paradigm 1: Fishery closures are the "maximizing" approach to successful rebuilding.

- Paradigm 2: A target stock level needs to be determined before economic considerations are addressed.

- Paradigm 3: An MSY target will provide sufficient stock to sustain a fishery.

- Paradigm 4: Bioeconomic analyses are too complex or contentious for policy use.

- Paradigm 5: Bioeconomic models are useless if they suggest unrealistic changes to fisheries.

While the biology and the economics of a fishery are always interconnected, a model that is weak on the economic aspects will tend to attribute all problems to the biology of the fishery. Conversely, an economic model that is weak on the biological aspects of the fishery will tend to attribute all problems to the economics of the fishery, whether or not these problems have economic causes. The usefulness of any model will be partially determined by the degree to which the analysts relied on overly simplistic assumptions for key components. And modelling the success of a rebuilding plan without incorporating the human dimensions of the harvest would be challenging at best, and misleading at worst. Modelling rebuilding also necessitates the examination of the path, and not simply the speed at reaching the target. This is where dynamic bioeconomic models can provide policy relevant information. There is a growing body of literature that uses stylized modes to show the potential for bioeconomic models to highlight the role of gear, multiple species, and stock characteristics in the development of management plans that ensure rebuilding while minimizing economic losses from reduced harvesting activity.

This paper described five fisheries where empirical bioeconomic models have been used to aid or evaluate rebuilding plans. The modelling aspect in these case studies shows simulations of different management alternatives that explicitly identify the tradeoffs and consequences of proposed decisions and, thereby, solidify the applicability of the bioeconomic modelling as a practical management tool. Many share two key commonalities. First, the policy-making process has developed into cooperation among stakeholders and management agencies. Second, the management agencies have been flexible enough to try and work around the needs of the industry, such as by making ad hoc changes to catch or effort levels prescribed by biological or bioeconomic models. Taken together, these case studies provide an example of how bioeconomic models have been used to evaluate economic and social objectives and search for better solutions in an attempt to become fundamental to the fishery, just like stock assessments. The fact that many bioeconomic models have not become fundamental to the management process suggests a lack of money, confidence in the approach, or legal support, or likely a combination. The irony is that without good economic analysis for multiple objectives, fisheries must rely on biological mandates developed in part because lawmakers and or policy makers do not trust the policy process.

In summary, an effective and responsible rebuilding plan should be more than simply estimating a long-run target and developing a rigid policy on how it is to be achieved. Fisheries are complex so simplistic solutions are likely inadequate. The use of bioeconomic models will be most effective when the data used capture the salient features 
of the particular fishery. The implication is that models should be tools of continual work in progress, adapting as fisheries change and updating as new information becomes available. Given that the Management Strategy Evaluation (MSE) approach attempts to gradually change management over time in response to particular control rules, bioeconomic models are well-suited to incorporate and evaluate the MSE paradigm for both retrospective analysis (a recent topic of increased research) and for future projections for rebuilding. This is where the emerging use of MSE holds promise; to teach managers, scientists, and user groups that effective fisheries management requires adaptability to and consideration of the unique contribution of both biological and economic information. 


\section{References}

Agar, J.J., and J.G. Sutinen. (2004). "Rebuilding Strategies for Multispecies Fisheries: A Stylized Bioeconomic Model." Environmental and Resource Economics 28: 1-29.

Anderson, L., and J.C. Seijo. (2009). Bioeconomics of Fisheries Management. New York: John Wiley \& Sons, Inc.

Anderson, L. (2002). "Report on the Bioeconomic Modelling Workshop.” July 23-25, 2002.

Available at:

www.asmfc.org/researchStatistics/cessBioecoModelWkshpReport.pdf.

Aps, R., L.T. Kell, H. Lassen, and I. Liiv. (2007). "Negotiation Framework for Baltic Fisheries Management: Striking the Balance of Interest." ICES Journal of Marine Science 64: 858861.

Armstrong, C.W., and U.R. Sumaila. (2000). "Cannibalism and the Optimal Sharing of the NorthEast Atlantic Cod Stock: a Bioeconomic Model.” Journal of Bioeconomics 2: 99-115.

Arnason, R., K. Kelleher, and R. Willmann. (2008). The Sunken Billions: The Economic Justification for Fisheries Reform. Joint publication of the World Bank and the FAO. ISBN 978-0-8213-7790-1.

Bue, B.G., R. Hilborn, and M.R. Link. (2008). "Optimal Harvesting Considering Biological and Economic Objectives.” Canadian Journal of Fisheries and Aquatic Sciences 65: 691-700.

Caddy, J.F., and D.J. Agnew. (2004). "An Overview of Recent Global Experience with Recovery Plans for Depleted Marine Resources and Suggested Guidelines for Recovery Planning." Reviews in Fish Biology and Fisheries 14: 43-112.

CEMARE. (2009). "Report on the Application of Bio-economic and Compliance Theory to Three Case Studies." UNCOVER Project No. 022717. Project co-funded by the European Commission within the Sixth Framework Programme (2002-2006). The Centre for the Economics and Management of Aquatic Resources (CEMARE), Department of Economics at the University of Portsmouth, Portsmouth, United Kingdom.

Clark, C.W. (1985). Bioeconomic Modelling and Fisheries Management. New York: John Wiley \& Sons, Inc.

. (1990). Mathematical Bioeconomics: The Optimal Management of Renewable Resources. New York: John Wiley \& Sons, Inc.

. (2006a). "Fisheries Bioeconomics: Why is it so Widely Misunderstood?" Population Ecology 48(2): 95-98.

. (2006b). The Worldwide Crisis in Fisheries: Economic Models and Human Behavior. Cambridge: Cambridge University Press.

Costello, C., S.D. Gaines, and J. Lynham. (2008). "Can Catch Shares Prevent Fisheries Collapse?" Science 321(5896): 1678-1681.

Dann, T., and S. Pascoe. (1994). "A Bioeconomic Model of the Northern Prawn Fishery." Australian Bureau of Agricultural and Resource Economics (ABARE), Research Report 94.13. Canberra, Australia.

Deroba, J.J., and J.R. Bence. (2008). "A Review of Harvest Policies: Understanding Relative Performance of Control Rules." Fisheries Research 94: 210-223.

De Young, C., A. Charles, and A. Hjort. (2008). "Human Dimensions of the Ecosystem Approach to Fisheries: An Overview of Context, Concepts, Tools and Methods," FAO Fisheries Technical Paper 489. Food and Agriculture Organization of the United Nations (FAO), Rome, Italy. 
Dichmont, C.M., A. Deng, A.E. Punt, N. Ellis, W.N. Venables, T. Kompas, Y. Ye, S. Zhou, J. Bishop. (2009). "Beyond Biological Performance Measures in Management Strategy Evaluation: Bringing in Economics and the Effects of Trawling on the Benthos." Fisheries Research 94(3): 238-250.

Dichmont, C.M., S. Pascoe, T. Kompas, A.E. Punt, and R. Deng. (2010). “On Implementing Maximum Economic Yield in Commercial Fisheries.” Proceedings of the National Academy of Sciences (PNAS) 107(1): 16-21.

Eggert, H. (1998). "Bioeconomic Analysis and Management." Environmental and Resource Economics 11(3-4): 399-411.

Frost, H., and P. Anderson. (2006). "The Common Fisheries Policy of the European Union and Fisheries Economics.” Marine Policy 30: 737-746.

Gates, J.M. (2009). "Investing in Our Future: The Economic Case for Rebuilding Mid-Atlantic Fish Populations.” Pew Environmental Group, Washington, D.C.

Gooday, P., T. Kompas, N. Che, and R. Curtotti. (2009). "Harvest Strategy Policy and Stock Rebuilding for Commonwealth Fisheries in Australia: Moving Towards MEY,” p. 49-72. In OECD Workshop on the Economics of Rebuilding Fisheries. Organization for Economic Cooperation and Development (OECD), Paris, France.

Gordon, H.S. (1954). "The Economic Theory of a Common Property Resource: The Fishery." Journal of Political Economy 82: 124-142.

Grafton, R.Q., T. Kompas, and R.W. Hilborn. (2007). "Economics of Overexploitation Revisited." Science 318: 1601

Hannesson, R. (1993). Bioeconomic Analysis of Fisheries. New York: John Wiley \& Sons, Inc.

Hilborn, R. (2002). “The Dark Side of Reference Points.” Bulletin of Marine Science 70: 403-408.

Hilborn, R., J.M. Orensanz, and A.M. Parma. (2005). "Institutions, Incentives and the Future of Fisheries.” Philosophical Transactions: Biological Sciences 360(1453): 47-57.

Holland, D.S. (2000). “A Bioeconomic Model of Marine Sanctuaries on Georges Bank.” Canadian Journal of Fisheries and Aquatic Sciences 57: 1307-1319.

Holland, D.S., N. Bentley, and P. Lallemand. (2005). “A Bioeconomic Analysis of Management Strategies for Rebuilding and Maintenance of the NSS Rock Lobster (Jasus edwardsii) Stock in Southern New Zealand." Canadian Journal of Fisheries and Aquatic Sciences 62(7): 1553 1569.

Holland, D.S., and G.E. Herrera (2009). "Uncertainty in the Management of Fisheries: Contradictory Implications and a New Approach.” Marine Resource Economics 24(3): 289 299.

Homans, F.R., and J.E. Wilen. (2005). "Markets and Rent Dissipation in Regulated Open Access Fisheries.” Journal of Environmental Economics and Management 49(2): 381-404.

Kahui, V., and W.R.J. Alexander. (2008). “A Bioeconomic Analysis of Marine Reserves for Pava (Abalone) Management of Stewart Island, New Zealand.” Environmental and Resource Economics 40: 339-367.

Khwaja, S. and A. Cox. (2009). "Rebuilding Fisheries: An Overview of Issues and Policy Approaches in the OECD," p. 5-26. In OECD Workshop on the Economics of Rebuilding Fisheries. OECD, Paris, France.

Knowler, D. (2002). “A Review of Selected Bioeconomic Models with Environmental Influences in Fisheries.” Journal of Bioeconomics 4: 163-181.

Kompas, T., and N. Che. (2004). "A Bioeconomic Model of the Australian Northern Prawn Fishery: Management Options under Uncertainty." ABARE, Commonwealth of Australia, Canaberra. 
Kompas, T., R.Q. Grafton, N. Che, and P. Gooday. (2009). "Development of Methods and Information to Support the Assessment of Economic Performance in Commonwealth Fisheries." ABARE report for the Fisheries Research and Development Corporation, Research Report 09.5, Canberra, Australia.

Lane, D.E., and B. Kaufmann. (1993). "Bioeconomic Impacts of TAC Adjustment Strategies: A Model Applied to Northern Cod." In Risk Evaluation and Biological Reference Points for Fisheries Management. Canadian Special Publication of Fisheries and Aquatic Sciences, eds. S.J. Smith, J.J. Hunt, and D. Rivard, 120: 387-402.

Lane, D.E. and H.P. Palsson. (1996). "Stock Rebuilding Strategies under Uncertainty: The Case for 'Sentinel' Fisheries." Canadian Journal of Economics 29: S151-156.

Larkin, S., and G. Sylvia. (1999). "Intrinsic Fish Characteristics and Intraseason Production Efficiency: A Management-level Bioeconomic Analysis of a Commercial Fishery." American Journal of Agricultural Economics 81(1): 29-43.

Larkin, S., and G. Sylvia. (2004). "Generating Enhanced Fishery Rents by Internalizing Product Quality Characteristics.” Environmental and Resource Economics 28(1): 101-122.

Larkin, S.L., G. Sylvia, M. Harte, and K. Quigley. (2006). "Optimal Rebuilding of Fish Stocks in Different Nations: Bioeconomic Lessons for Regulators." Marine Resource Economics 21: 395-413.

Marsden, A.D., S.J. Martell, and U.R. Sumaila. (2009). "Retrospective Bioeconomic Analysis of Fraser River Sockeye Salmon Fishery Management." Fisheries Research 97(1): 32-41.

Martell, S. and C.J. Walters. (2008). "Experimental Policies for Rebuilding Depleted Stocks." Canadian Journal of Fisheries and Aquatic Sciences 65: 1601-1609.

Martinet, V., O. Thébaud, and L. Doyen. (2007). "Defining Viable Recovery Paths Toward Sustainable Fisheries." Ecological Economics 64: 411-422.

Merino, G., F. Maynou, and A. García-Olivares. (2007). "Effort Dynamics in a Fisheries Bioeconomic Model: A Vessel Level Approach through Game Theory.” Scientia Marina 71(3): doi:10.3989/ scimar.2007.71n3537.

Milon, J.W., S.L. Larkin, and N.E. Ehrhardt. (1999). "Bioeconomic Models of the Florida Commercial Spiny Lobster Fishery." Florida Sea Grant Report Number 117. FLSGP-T-99002. Florida Sea Grant, Gainesville, Florida.

Munro, G. (2009). "Getting the Economics and the Incentives Right: Instrument Choices in Rebuilding Fisheries," p. 27-47. In OECD Workshop on the Economics of Rebuilding Fisheries. OECD, Paris, France.

Pascoe, S., and S. Mardle. (2001). "Optimal Fleet Size in the English Channel: A Multi-objective Programming Approach.” European Review of Agricultural Economics 28(2): 161-185.

Penas, E. (2007). "The Fishery Conservation Policy of the European Union after 2002: Towards Long-term Sustainability." ICES Journal of Marine Science 64: 588-595.

Rayns, N. (2007). "The Australian Government's Harvest Strategy Policy." ICES Journal of Marine Science 64: 596-598.

Rettig, R.B. (1987). "Bioeconomic Models: Do They Really Help Fishery Managers?" Transactions of the American Fisheries Society 16: 405-411.

Richey, S. (2004). "NORMAC 56 - Economic Efficiency Considerations for the NPF." Summary to all Statutory Fishing Rights (SFRs) Holders. Northern Prawn Fishery Management Advisory Committee (NORMAC). Fremantle, Australia.

Rosenberg, A.A., J.H. Swasey, and M. Bowman. (2006). "Rebuilding US Fisheries: Progress and Problems." Frontiers in Ecology and the Environment 4(6): 303-308.

Sanchirico, J.N. (2005). "Additivity Properties in Metapopulation Models: Implications for the Assessment of Marine Reserves." Journal of Environmental Economics and Management 49(1): 1-25. 
Safina, C., A.A. Rosenberg, R.A. Myers, T.J. Quinn II, and J.S. Collie. (2005). "United States Ocean Fish Recovery: Staying the Course.” Science 309(5735): 707-708.

Sandberg, P. (2005). "Harvest Rules when Price Depends on Quantity: The Case of Norwegian Spring Spawning Herring (Clupea harengus L.).” Marine Resource Economics 20: 287-303. (2009). "Rebuilding the Stock of Norwegian Spring Spawning Herring - Lessons Learned," p. 145-157. In OECD Workshop on the Economics of Rebuilding Fisheries. OECD, Paris, France.

Schaefer, M.B. (1954). "Some Aspects of the Dynamics of Populations." Bulletin of the InterAmerican Tropical Tuna Commission 1: 26-56.

Seijo, J.C., O. Defeo, and S. Salas. (1998). Fisheries Bioeconomics: Theory, Modelling and Management. FAO Fisheries Technical Paper 368. Food and Agriculture Organization of the United Nations (FAO), Rome, Italy.

Smith, M.D. (2008). "Bioeconometrics: Empirical Modelling of Bioeconomic Systems." Marine Resource Economics 23(1): 1-24.

Smith, M.D. and J.E. Wilen. (2003). "Economic Impacts of Marine Reserves: The Importance of Spatial Behavior.” Journal of Environmental Economics and Management 46(2): 183-206.

Stolpe, N. (2008). “ 'Optimum Yield' in Fisheries is far from Optimum: Maximum Sustainable Yield and Effective Fisheries Management." FishNet USA, 7 p. Available from http://www.fishnet-usa.com.

Sumaila, U.R., and E. Suatoni. (2005). "Fish Economics: The Benefits of Rebuilding United States Ocean Fish Populations." Fisheries Economics Research Unit, University of British Colombia, Vancouver, Canada, United States

Sylvia, G. (1997). "Generating Information for Aquaculture Development: The Art and Science of Economic Policy Modelling." Aquaculture Economics and Management 1(1): 87-98.

Sylvia, G., and D. Cai. (1995). "Generating Policy Information for Fisheries Management: A Comparison of Alternative Approaches.” Marine Resource Economics 9: 311-328.

Sylvia, G., and R.R. Enriquez. (1994). "Multiobjective Bioeconomic Analysis: An Application to the Pacific Whiting Fishery.” Marine Resource Economics 9: 311-328.

Tahvonen, O. (2009). “Optimal Harvesting of Age-structured Fish Populations.” Marine Resource Economics 24(2): 147-169.

Ulrich, C., B. Andersen, S. Sparre, and J.R. Nielsen. (2007). "TEMAS: Fleet-based Bio-Economic Simulation Software to Evaluate Management Strategies Accounting for Fleet behaviour." ICES Journal of Marine Science 64: 647-651.

Ward, J.M., and M. Kelly. (2009). "Measuring Management Success: Experience with United States Fisheries." Marine Policy 33(1): 164-171.

Whitmarsh, D., C. James, H. Pickering, and A. Neiland. (2000). "The Profitability of Marine Commercial Fisheries: A Review of Economic Information Needs with Particular Reference to the UK." Marine Policy 24: 257-263.

Wiedenmann, J., and M. Mangel. (2006). "A Review of Rebuilding Plans for Overfished Stocks in the United States: Identifying Situations of Special Concern.” Lenfest Ocean Program Research Series, Lenfest Ocean Program, Washington, D.C., United States

Worm, B., R. Hilborn, J.K. Baum, T.A. Branch, J.S. Collie, C. Costello, M.J. Fogarty, E.A. Fulton, J.A. Hutchings, S. Jennings, O.P. Jensen, H.K. Lotze, P.M. Mace, T.R. McClanahan, C. Minto, S.R. Palumbi, A.M. Parma, D. Ricard, A.A. Rosenberg, R. Watson, D. Zeller. (2009). "Rebuilding Global Fisheries." Science 325: 578-584. 